\title{
Factors that impact on the perception of menstruation among female adolescents
}

\author{
Juana Serret-Montoya, M.D. ${ }^{a}$, Miguel A. Villasis-Keever, M.D. ${ }^{b}$, \\ María O. Mendoza-Rojas, M.D. ${ }^{a}$, Flor Granados-Canseco, M.D. ${ }^{c}$, \\ Eira A. Zúñiga-Partida, M.D. ${ }^{c}$ and Jessie N. Zurita-Cruz, M.D. ${ }^{d}$
}

\begin{abstract}
Introduction. It has been described that menstruation is perceived as a natural but cumbersome event, with a negative impact on women's daily life. The objective of this study was to identify the perception of menstruation among female adolescents and the factors that may affect it.

Material and methods. Observational, crosssectional, comparative study in postmenarcheal adolescents with and without chronic conditions in two children's hospitals and two primary and secondary schools. Age, education level, type of population, date of menarche, and presence of dysmenorrhea were recorded. A previously validated questionnaire was administered to assess the perception of menstruation.

Results. A total of 346 female adolescents were included. The most common perception of menstruation was negative in $65.6 \%(\mathrm{n}=227)$, positive in $16 \%(n=55)$, discreet in $13 \%(n=45)$, and indefinite in $5.4 \%(\mathrm{n}=19)$. The presence of a chronic condition demonstrated to be a protective factor against a negative perception of menstruation (odds ratio: 0.4 [95\% confidence interval: $0.20-0.78], p=0.007$ ).

Conclusions. More than half of female adolescents had a negative attitude toward menstruation, but the presence of a chronic condition improved it. Key words: adolescents, perception, menstruation, chronic condition.
\end{abstract}

http:/ / dx.doi.org/10.5546/aap.2020.eng.e126

To cite: Serret-Montoya J, Villasís-Keever MA, Mendoza-Rojas MO, Granados-Canseco F, et al. Factors that impact on the perception of menstruation among female adolescents. Arch Argent Pediatr 2020;118(2):e126-e134.

\section{INTRODUCTION}

Women's perception of menstruation is varied and depends on many factors, particularly women's age, ${ }^{1-3}$ daily activities, ${ }^{4}$ the presence of dysmenorrhea, ${ }^{5,6}$ and cultural and family conditions. ${ }^{7,8}$ The studies done in adult women revealed that almost one third of studied women had reported that their menstrual period had a major negative impact on their daily life, especially in relation to their sex life and the practice of sports. ${ }^{9}$

The perception of menstruation among adolescents depends on their attitude at its onset; whether it is negative or positive, it will remain the same for the subsequent menstrual cycles. Women who had a positive attitude toward their body image and health behaviors had a positive perception of menstruation. ${ }^{10}$

Multiple questionnaires have been developed to assess the impact of menstruation on women, $;, 11,12$ the "Beliefs About and Attitudes Toward Menstruation (BATM)" has been particularly used in several studies ${ }^{1,2,12,13}$ (Annex). It identifies negative, positive, and discreet perceptions that are equivalent to embarrassment, shame or secrecy. A perception of shame or secrecy toward menstruation may condition women to misidentify -because they do not want to talk about it- the difference between normal and pathological conditions related to menstruation. ${ }^{12}$

Female adolescents with chronic conditions are in contact with health care providers, so they may have a better perception of menstruation because they are better informed. No studies have analyzed whether the perception of menstruation is affected 
when women's health is modified by the history of a chronic condition, the stage of puberty, and the type of population (rural/urban).

The objective of this study was to identify the perception of menstruation among female adolescents and the factors that may affect it, especially among adolescents with and without chronic conditions.

\section{METHODS AND MATERIALS}

This study was conducted between January and June 2017 at two tertiary care children's hospitals that provide services to patients with chronic conditions (Hospital de Pediatría, Centro Médico Nacional Siglo XXI, and Hospital Infantil de México Federico Gómez) and at two public primary and secondary schools in Mexico City. Schools were selected by convenience based on their proximity to the children's hospitals included in the study.

All included patients were selected by nonprobability sampling. The study had a crosssectional, comparative design in a group of female adolescents. Inclusion criteria were female adolescents aged 10-18 years who had experienced menarche at the time of completing the questionnaire. Patients who did not agree to participate, could not read or write or had not fully completed the questionnaire were excluded.

Female adolescents with chronic conditions were invited to participate while in the waiting room, before going into the physician's office at each of the participating hospitals. The pediatrician conducted the interview. Data on age, education level, type of population, date of menarche, presence of dysmenorrhea and of chronic conditions were recorded.

A chronic condition was defined as a disease with more than 3 months of history. ${ }^{14,15}$ The stage of adolescence was classified into early (10-13 years), middle (14-16 years), and late (17-18 years). Dysmenorrhea was defined as the presence of pain during menstruation. The type of population was defined as urban, when patients lived in a population with more than 5000 inhabitants without agricultural activities, or as rural, when the population was made up of less than 5000 inhabitants with agricultural activities.

The survey mentioned above included 25 items and its completion took approximately 15 minutes. It was administered in a quiet room, without noise or distractions. Each item was designed to evoke an attitude toward menstruation using a Likertlike scale; 10 items referred to positive attitudes

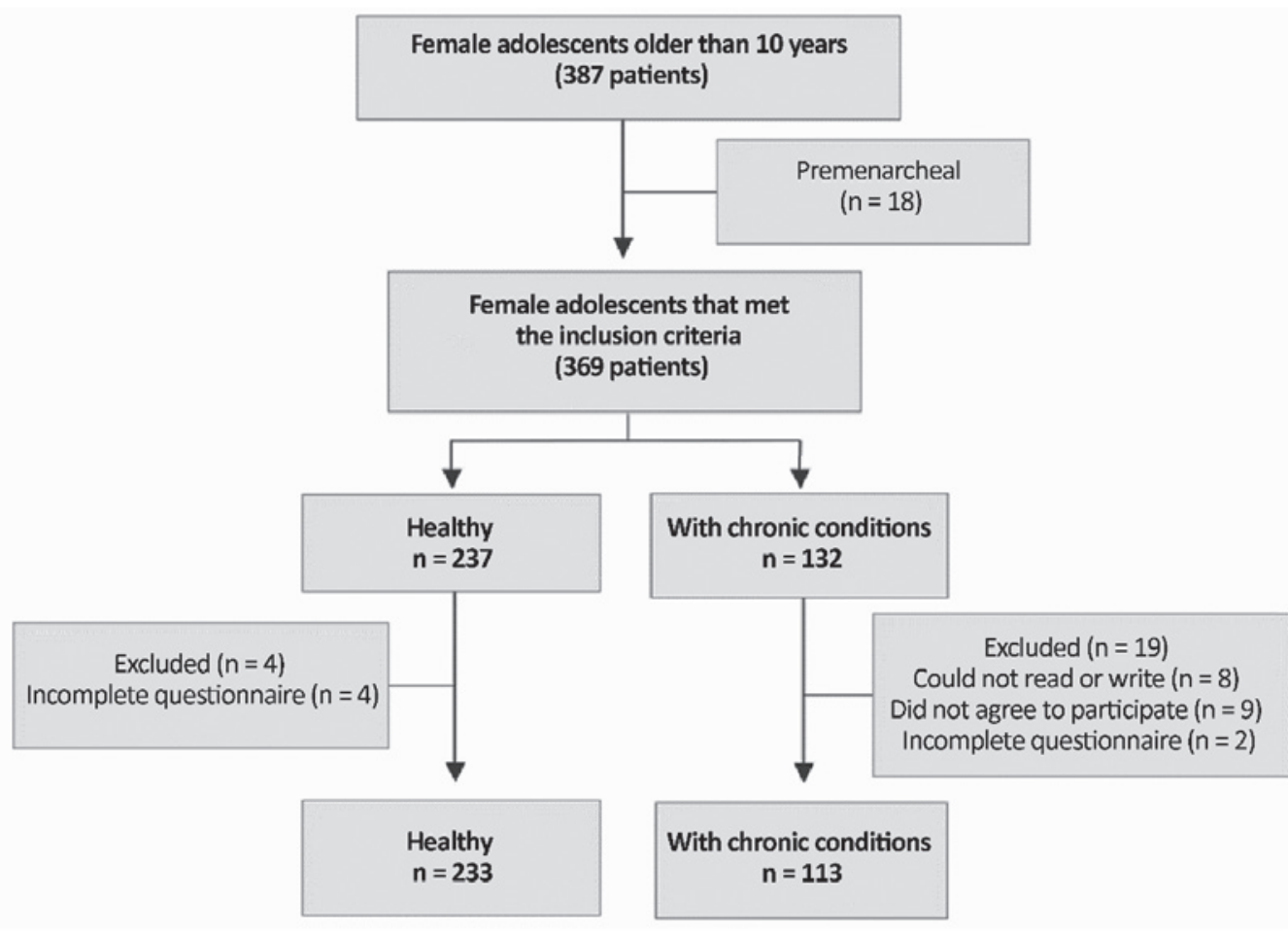


toward menstruation; 9 to negative attitudes; and 6 to shameful attitudes., ${ }^{2,12}$ The questionnaire had been validated among Spanish-speaking female adolescents, specifically from Mexico. ${ }^{14}$

The research protocol was approved by the hospital's Ethics and Research Committee under number R-2014-3603-21. Education authorities were asked for their approval to conduct the interview and administer the survey at participating schools. Parents signed an informed consent, and adolescents signed an assent form based on the recommendations by the Declaration of Helsinki.

\section{Statistical analysis}

For the descriptive analysis, qualitative outcome measures were expressed as absolute frequency and percentage. The Shapiro-Wilk test was used for quantitative outcome measures; after establishing a normal distribution, the mean and standard deviation were estimated.

Adolescents were divided into 3 groups based on their perception of menstruation: indefinite, positive, and negative or shameful. An analysis of variance (ANOVA) and the Bonferroni test were done to compare quantitative outcome measures among groups, whereas a $\chi^{2}$ test was used for

TABLE 1. Demographic characteristics of the surveyed patients $(n=346)$

\begin{tabular}{lc}
\hline Characteristics & $\mathbf{n}(\%)$ \\
\hline Age (years)* & $13.5 \pm 1.3$ \\
Stage of adolescence & \\
$\quad$ Early (9-13 years) & $171(49.4)$ \\
$\quad$ Middle (14-16 years) & $171(49.4)$ \\
$\quad$ Late (17-20 years) & $4(1.2)$ \\
Education & \\
$\quad$ Primary school & $39(11.3)$ \\
$\quad$ Junior high school & $278(80.3)$ \\
$\quad$ High school & $29(8.4)$ \\
Type of population & \\
$\quad$ Rural & $287(82.9)$ \\
$\quad$ Urban & $59(17.1)$ \\
Gynecological age & \\
$\quad<1$ year & $145(41.9)$ \\
2-3 years & $147(42.5)$ \\
$\quad>3$ years & $54(15.6)$ \\
Presence of dysmenorrhea & $240(69.4)$ \\
Chronic condition & \\
Without & $233(67.3)$ \\
With & $113(32.7)$ \\
\hline
\end{tabular}

* Mean \pm standard deviation. qualitative ones. A $p$ value $<0.05$ was considered statistically significant. The statistical software package STATA v.11 was used.

\section{RESULTS}

Among patients with chronic conditions, 132 met the selection criteria; however, a total of 19 were excluded: 8 could not read or write, 9 did not agree to participate, and 2 had incomplete questionnaires. Among healthy adolescents, 237 met the selection criteria and 4 were excluded because of incomplete questionnaires (Figure 1).

The average age of the 346 included adolescents was $13.5 \pm 1.3$ years. Based on the stage of adolescence, a half of adolescents were in the early stage $(49.4 \%, \mathrm{n}=171)$ and the other half, in the middle stage $(49.4 \%, \mathrm{n}=171)$, whereas only $1.2 \%(n=4)$ were in the late stage. Most participants $(80.3 \%)$ were in junior high school. Participants were predominantly from urban populations $(82.9 \%, \mathrm{n}=287)$ compared to rural populations (Table 1).

All adolescents who completed the survey were asked about their age when they had experienced menarche to establish their gynecological age. The average age at menarche was $11.5 \pm 1.1$ years, and $84.4 \%(n=292)$ of adolescents had a gynecological age of less than 3 years (gynecological age $<1$ year: $\mathrm{n}=145 ; 2-3$ years: $\mathrm{n}=147 ;>3$ years: $\mathrm{n}=54$ ). Another aspect taken into consideration in the questionnaire was the presence of dysmenorrhea during their periods, which was present in $240(69.4 \%)$.

The level of education of adolescents with chronic conditions corresponded to high school in $25 \%$; half of patients lived in a rural population. In relation to the departments providing services to the patients with chronic conditions, practically all specialties were mentioned, but more than half of patients were seen at the Department of Nephrology $(\mathrm{n}=15,13.3 \%)$, Oncology $(\mathrm{n}=14$, $12.4 \%)$, Pediatrics $(\mathrm{n}=13,11.5 \%)$, Rheumatology $(\mathrm{n}=12,10.6 \%)$, Hematology $(\mathrm{n}=10,8.8 \%)$, Endocrinology $(n=9,8 \%)$, Neurology $(n=6$, $5.3 \%)$, Gastroenterology $(\mathrm{n}=6,5.3 \%)$, and others $(\mathrm{n}=26,23 \%)$. The time of the clinical course of chronic conditions ranged from less than a year up to 17 years, with an average of 4.5 years.

In relation to questionnaire answers, the predominance of a perception toward menstruation was assessed and weighed up; the most common perception was negative or shameful, with a rate of $78.6 \%(n=272)$, followed 
by a positive perception in $15.9 \%(\mathrm{n}=55)$. In $5.5 \%(n=19)$ of participating adolescents, it was not possible to determine a predominant perception because their score in relation to each attitude in the original survey was equally low for the three analyzed perceptions, so these patients were classified as having an indefinite perception toward menstruation (Table 2).

The general adolescents' characteristics used to compare the perception of menstruation were age, type of population, stage of adolescence, level of education, gynecological age, presence of dysmenorrhea, and presence of chronic conditions. It was observed that adolescents who lived in an urban population $(86.4 \%$ versus
$69.1 \%, p=0.004)$ and those without chronic conditions $(71.3 \%$ versus $28.7 \%, p<0.009)$ had a greater negative perception (Table 2).

When comparing the negative perception of menstruation between adolescents with and without chronic conditions, a statistically significant difference was observed in terms of age, stage of adolescence, level of education, type of population, gynecological age, and presence of dysmenorrhea. The multivariate analysis identified that the presence of a chronic condition was a protective factor against a negative perception of menstruation (odds ratio [OR]: 0.4 [95\% confidence interval \{CI\}: 0.20-0.78], $p=0.007$ ) (Table 3).

TABLE 2. Perception of menstruation based on the general characteristics of the 346 female adolescents

\begin{tabular}{|c|c|c|c|c|c|}
\hline Characteristics & & $\begin{array}{l}\text { Indefinite } \\
\qquad \begin{array}{c}\text { n }=19 \\
5,5 \% \\
\text { n }(\%)\end{array}\end{array}$ & $\begin{array}{c}\text { Positive } \\
\text { n }=55 \\
15,9 \% \\
\text { n }(\%) \\
\end{array}$ & $\begin{array}{l}\text { Negative or shameful } \\
\qquad \begin{array}{c}\mathrm{n}=272 \\
78,6 \% \\
\mathrm{n}(\%)\end{array} \\
\end{array}$ & $p$ \\
\hline Age (years)* & & $13.6 \pm 1.4$ & $13.5 \pm 1.3$ & $13.4 \pm 1.3$ & 0.17 \\
\hline Stage of adolescence & $\begin{array}{l}\text { Early } \\
\text { Middle } \\
\text { Late }\end{array}$ & $\begin{array}{c}6(31.6) \\
13(68.4) \\
-\end{array}$ & $\begin{array}{c}24(43.6) \\
31(56.4) \\
-\end{array}$ & $\begin{array}{c}141(51.8) \\
127(46.7) \\
4(1.5)\end{array}$ & 0.25 \\
\hline Education & $\begin{array}{l}\text { Primary school } \\
\text { Junior high school } \\
\text { High school }\end{array}$ & $\begin{array}{c}4(21) \\
12(63.2) \\
3(15.8)\end{array}$ & $\begin{array}{c}7(12.7) \\
41(74.6) \\
7(12.7)\end{array}$ & $\begin{array}{c}28(10.3) \\
225(82.7) \\
19(7)\end{array}$ & 0.008 \\
\hline Type of population & $\begin{array}{l}\text { Urban } \\
\text { Rural }\end{array}$ & $\begin{array}{c}14(73.7) \\
5(26.3)\end{array}$ & $\begin{array}{l}38(69.1) \\
17(30.9)\end{array}$ & $\begin{array}{c}235(86.4) \\
37(13.6)\end{array}$ & 0.004 \\
\hline Gynecological age & $\begin{array}{l}<1 \text { year } \\
2-3 \text { years } \\
>3 \text { years }\end{array}$ & $\begin{array}{l}10(52.6) \\
7(36.9) \\
6(31.6)\end{array}$ & $\begin{array}{l}19(34.5) \\
32(58.2) \\
17(30.1)\end{array}$ & $\begin{array}{l}116(42.6) \\
108(39.7) \\
48(17.7)\end{array}$ & 0.072 \\
\hline Presence of dysmenorrhea & & $13(68.4)$ & $38(69.1)$ & $189(69.5)$ & 0.99 \\
\hline Chronic condition & $\begin{array}{l}\text { Without } \\
\text { With }\end{array}$ & $\begin{array}{c}11(57.9) \\
8(42.1)\end{array}$ & $\begin{array}{l}28 \text { (50.9) } \\
27(49.1)\end{array}$ & $\begin{array}{c}194(71.3) \\
78(28.7)\end{array}$ & 0.009 \\
\hline
\end{tabular}

${ }^{*}$ Mean \pm standard deviation.

Analysis of variance (ANOVA) in years. $\chi^{2}$ test for proportions.

TABLE 3. Multivariate analysis of factors related to a negative or shameful perception of menstruation among analyzed female adolescents

\begin{tabular}{|c|c|c|c|c|}
\hline \multirow[b]{2}{*}{ Chronic condition } & \multirow{2}{*}{$\begin{array}{c}\text { OR } \\
0.4\end{array}$} & \multicolumn{2}{|c|}{$95 \% \mathrm{CI}$} & \multirow{2}{*}{$\frac{p}{0.007}$} \\
\hline & & 0.20 & 0.78 & \\
\hline Age (years) & 1.06 & 0.70 & 1.60 & 0.780 \\
\hline Stage of adolescence & 0.51 & 0.20 & 1.25 & 0.144 \\
\hline Education & 1.23 & 0.61 & 2.46 & 0.549 \\
\hline Type of population & 0.65 & 0.30 & 1.40 & 0.278 \\
\hline Gynecological age (years) & 1.26 & 0.80 & 1.99 & 0.299 \\
\hline Dysmenorrhea & 1.08 & 0.64 & 1.82 & 0.763 \\
\hline
\end{tabular}

OR: odds ratio; CI: confidence interval. 


\section{DISCUSSION}

A negative perception was smaller among female adolescents with chronic conditions compared to healthy ones. The bibliography points out that attitudes toward menstruation are variable and depend on age and socioeconomic factors, among others. ${ }^{10,15-17}$ In a study conducted in eight different countries, only a third of surveyed women reported a negative impact of menstruation in their lives, whereas, in another study in women taking birth control pills, women who lived in predominantly Catholic countries and young women preferred amenorrhea over regular menstrual cycles., ${ }^{9,18}$

In relation to the influence of dysmenorrhea on the perception of menstruation, in 2013, Pitangui et al., carried out a study in adolescents in Brazil and found that, out of 218 healthy female adolescents, $73 \%$ referred dysmenorrhea. ${ }^{4}$

In the study by Houston et al., 184 adolescents were surveyed, and the rate of dysmenorrhea was $65 \% .^{5}$ In our study, it was observed that the rate of dysmenorrhea among healthy adolescents was similar to that reported in other studies, whereas patients with chronic conditions showed a lower rate, which may have impacted their perception of menstruation, because, in particular, the percentage of negative attitudes was higher among healthy adolescents with dysmenorrhea compared to adolescents with chronic conditions.

Brooks-Gunn et al., ${ }^{19}$ assessed the perception of menstruation in adolescents before and after menarche and observed that it was better after menarche. Likewise, Marván et al., ${ }^{2}$ described, in healthy female adolescents (from $5^{\text {th }}$ grade in primary school to high school), that those who experienced menarche before 11 years old more frequently had a negative or shameful perception compared to those who experienced menarche at an older age. This was similar to the findings of our study: at a younger age, adolescents tended to have a more negative attitude. It could be said that the perception of menstruation varies depending on the age at menarche; i.e., at an older age, adolescents had a better acceptance of menstruation.

In addition, a relevant finding of the analysis of adolescents' answers was that $13 \%$ were not able to determine the presence of a positive, negative or shameful attitude or perception because their answers did not point toward any of the three. In relation to this, the assessment method used in our study does not appear to be very accurate for our study group because the population included the three stages of adolescence, with a higher percentage of participants in middle adolescence. The survey had been validated in studies with younger participants who were mostly in the early stage of adolescence.

It is worth noting that there are other factors that may affect the perception of menstruation and that were not assessed in this study. As mentioned before, the sources of information from which adolescents get an idea of menstruation have a direct effect on this configuration. It is known that one of the main sources of information is the family, specifically mothers, so their perception could be compared to that of adolescents; those results could be taken into consideration for future studies. Other relevant factors to be considered include the phase of the menstrual cycle of the patient because, in some studies, it has been observed that women's perception of different situations may change depending on their hormone levels during the different phases of menstruation, ${ }^{20}$ and the presence of premenstrual syndrome, whose signs and symptoms are probably unknown to many of these adolescents due to a lack of information and knowledge of their bodies, thus impacting their perception in a more negative manner.

This study shows that female adolescents have a different perception of menstruation based on certain factors in their setting. For example, those with a chronic condition perceive menstruation, preferably, as a positive event. This may be because they are more commonly in contact with health care providers. In this regard, it is worth mentioning that the participating hospitals had an adolescent clinic available. Thus, one of the activities offered by these clinics included explaining that menstruation is part of the normal pubertal development and that having it meant an adequate health status and, indirectly, a better control of chronic conditions. This implies creating a setting of trust in the medical office, where adolescents can state their doubts, especially in relation to menstruation.

In general, it could be said that a high negative perception was identified because of the insufficient information received by female adolescents on menstruation. ${ }^{21}$ In Mexico, students receive comprehensive sex education (CSE) while in junior high school, i.e., between 12 and 16 years old, but, according to the reports, only $55 \%$ of adolescents take part in the course, and the proportion of CSE is higher in urban areas. ${ }^{22}$ Such low percentage of CSE among adolescents explains 
why such a natural event that is an integral part of a woman's life shows such a high rate of negative or shameful perception. As a result, female adolescents are missing a chance to receive guidance on menstruation-related problems, an early diagnosis, and specialized treatment.

In this context, we propose administering a standardized questionnaire on the perception of menstruation as part of the routine care of female adolescents in children's hospitals and promoting, at school, talks on menstruation as a natural event that reflects women's good health status.

\section{CONCLUSIONS}

In general, more than half of female adolescents had a negative attitude toward menstruation; however, the presence of a chronic condition improved such attitude.

\section{REFERENCES}

1. Marván ML, Molina-Abolnik M. Mexican adolescents' experience of menarche and attitudes toward menstruation: role of communication between mothers and daughters. $J$ Pediatr Adolesc Gynecol. 2012; 25(6):358-63.

2. Marván ML, Vacio A, García-Yañez G, EspinosaHernández G. Attitudes toward menarche among Mexican preadolescents. Women Health. 2007; 46(1):7-23.

3. Jarrah S, Kamel A. Attitudes and practices of schoolaged girls towards menstruation. Int J Nurs Pract. 2012; 18(3):308-15.

4. Pitangui A, Gomes M, Lima A, Shwingel P, et al. Menstruation disturbances: prevalence, characteristics, and effects on the activities of daily living among adolescent girls from Brazil. J Pediatr Adolesc Gynecol. 2013; 26(3):148-52.

5. Houston A, Abraham A, Huang Z, D $\square$ Angelo L. Knowledge, attitudes, and consequences of menstrual health in urban adolescent females. J Pediatr Adolesc Gynecol. 2006; 19(4):271-5.

6. Szúcs M, Bitó T, Csíkos C, PárduczSzöllősi A, etal. Knowledge and attitudes of female university students on menstrual cycle and contraception. J Obstet Gynaecol. 2017; 37(2):210-4.

7. Roberts T. Female trouble: the menstrual self-evaluation scale and women's self-objectification. Psychol Women $Q$. 2004; 28(1):22-6.

8. Bramwell R, Biswas E, Anderson C. Using the menstrual attitude questionnaire with a British and an Indian sample. J Reprod Infant Psychol. 2002; 20(3):159-70.
9. Szarewski A, Von Stenglin A, Rybowski S. Women's attitudes towards monthly bleeding: results of a global population-based survey. Eur J Contracept Reprod Health Care. 2012; 17(4):270-83.

10. McPherson M, Korfine L. Menstruation across time: Menarche, menstrual attitudes, experiences, and behaviors. Womens Health Issues. 2004; 14(6):193-200.

11. Chrisler JC, Marván ML, Gorman JA, Rossini M. Body appreciation and attitudes toward menstruation. Body Image. 2015; 12:78-81.

12. Marván ML, Ramírez-EsparzaD, Cortés-Iniestra S, Chrisler J. Development of a new scale to measure Beliefs about and Attitudes Toward Menstruation (BATM): data from Mexico and the United States. Health Care Women Int. 2006; 27(5):453-73.

13. Marván ML, Bejarano J. Premenarcheal Mexican girls' and their teachers' perceptions of preparation students receive about menstruation at school. J Sch Health. 2005; 75(3):86-9.

14. Marván M, Molina Abolnik M. Validación en México de un cuestionario de actitudes hacia la menstruación dirigido a adolescentes posmenarcas. Psicol Salud. 2002; 12(2):173-8.

15. Metusela C, Ussher J, Perz J, Hawkey A, et al. "In My Culture, We Don't Know Anything About That": Sexual and Reproductive Health of Migrant and Refugee Women. Int J Behav Med. 2017; 24(6):836-45.

16. Sveinsdóttir H. Menstruation, objectification and healthrelated quality of life: A questionnaire study. J Clin Nurs. 2018; 27(3-4):e503-13.

17. Tan DA, Haththotuwa R, Fraser I. Cultural aspects and mythologies surrounding menstruation and abnormal uterine bleeding. Best Pract Res Clin Obstet Gynaecol. 2017; 40:121-33.

18. Fiala C, Chabbert-BuffetN,Häusler G, Jamin C, etal.Women's preferences for menstrualbleeding frequency in 12 European countries: the Inconvenience Due to Women's Monthly Bleeding (ISY) survey. Eur J Contracept Reprod Health Care. 2017; 22(4):268-73.

19. Brooks-Gunn J, Ruble D. The development of menstrualrelated beliefs and behaviors during early adolescence. Chil Dev. 1982; 53(6):1567-77.

20. American Academy of Pediatrics Committee on Adolescence; American College of Obstetricians and Gynecologists Committee on Adolescent Health Care, Diaz A, Laufer MR, Breech L. Menstruation in girls and adolescents: using the menstrual cycle as a vital sign. Pediatrics. 2006; 118(5):2245-50.

21. Chandra-Mouli V, Patel S. Mapping the knowledge and understanding of menarche, menstrual hygiene and menstrual health among adolescent girls in low- and middle-income countries. Reprod Health. 2017; 14(1):30.

22. Rojas R, Castro F, Villalobos A, Allen-Leigh B, et al. Educación sexual integral: cobertura, homogeneidad, integralidad y continuidad en las escuelas de México. Salud Pública Méx. 2017; 59(1):19-27. 
ANNEX

Questionnaire "Beliefs about and attitudes toward menstruation"

Name:

Date:

Instructions: Mark with an X the answer that best describes how you feel about each statement.

There are no right or wrong answers.

1 I feel proud when I am having my period.

2 I feel very happy to know I am having my period.

3 I feel happy when I think about my period.

4 When I have my period, I feel good.

5 I feel good when I have my o Strongly agree. period.

6 I feel excited when I am having my period.

7 I feel special when I am having my period.

8 I was eager to have my first o Strongly agree. period.

9 I was happy when I found out about the period.

10 I am happy because I am old enough to have my period.

11 When girls are having their period, they should be allowed to stay at home.

12 I feel different when I am having my period.

13 Simply the fact of having my period makes me feel uncomfortable.

14 It is OK if girls miss school if they are having menstrual cramps during their period.

15 Every time girls are having their periods, they should be allowed to miss physical education classes.

o Strongly agree. o Strongly agree. o Strongly agree.

o Strongly agree.

o Strongly agree.

Strongly agree.

o Strongly agree.

o Strongly agree. o Strongly agree. o Slightly agree. o Neither agree nor disagree.

o Slightly agree.

o Neither agree nor disagree.

o Strongly agree. o Slightly agree. o Neither agree nor disagree.

o Strongly agree. o Slightly agree.

o Slightly agree. o Neither agree nor disagree. Slightly agree.

o Slightly agree. $\quad$ Neither agree
nor disagree.

o Slightly agree. $\quad$ Neither agree
nor disagree.

o Neither agree nor disagree.

o Slightly agree.

o Neither agree nor disagree.

o Strongly agree. o Slightly agree. o Neither agree nor disagree. o Slightly disagree.

o Strongly

Slightly o Strongly

disagree. disagree.

o Slightly o Strongly

disagree. disagree.

$\begin{array}{cr}\begin{array}{c}\text { o Slightly } \\ \text { disagree. }\end{array} & \begin{array}{r}\text { o Strongly } \\ \text { disagree. }\end{array} \\ \begin{array}{c}\text { o Slightly } \\ \text { disagree. }\end{array} & \begin{array}{r}\text { o Strongly } \\ \text { disagree. }\end{array} \\ \text { o Slightly } & \text { o Strongly } \\ \text { disagree. } & \text { disagree. } \\ \text { o Slightly } & \text { o Strongly } \\ \text { disagree. } & \text { disagree. } \\ \text { o Slightly } & \text { o Strongly } \\ \text { disagree. } & \text { disagree. } \\ \text { o Slightly } & \text { o Strongly } \\ \text { disagree. } & \text { disagree. } \\ \text { o Slightly } & \text { o Strongly } \\ \text { disagree. } & \text { disagree. } \\ \text { o Slightly } & \text { o Strongly } \\ \text { disagree. } & \text { disagree. } \\ \text { o Slightly } & \text { o Strongly } \\ \text { disagree. } & \text { disagree. } \\ \text { o Slightly } & \text { o Strongly } \\ \text { disagree. } & \text { disagree. }\end{array}$

o Slightly o Strongly

disagree. disagree.

o Slightly o Strongly disagree. disagree. 
16 During the period, something is not right.

17 I feel scared because I do not know what is happening when I am having my period.

18 Girls should be worried when they are having their period.

19 I am really worried that my period will start when I am not expecting it.

20 I feel uncomfortable talking o Strongly agree. o Slightly agree. about the period with my friends.

21 I live in fear of people knowing that I am having my period.

22 It is embarrassing to ask questions about the period.

23 When I am having my period, I fear boys will find out.

24 Girls feel uncomfortable when the topic of the period is discussed at school.

25 Every time someone mentions the word "period," I get nervous.

o Strongly agree. o Slightly agree.

o Strongly agree. o Slightly agree.

o Strongly agree. o Slightly agree.

o Strongly agree. o Slightly agree. o Strongly agree. o Slightly agree. o Neither agree nor disagree.

o Neither agree nor disagree.

$\begin{array}{cr}\begin{array}{c}\text { o Slightly } \\ \text { disagree. }\end{array} & \begin{array}{r}\text { o Strongly } \\ \text { disagree. }\end{array} \\ \text { o Slightly } & \text { o Strongly } \\ \text { disagree. } & \text { disagree. }\end{array}$

o Strongly agree. o Slightly agree. o Neither agree nor disagree.

$$
\begin{array}{rr}
\text { o Slightly o Strongly } \\
\text { disagree. } & \text { disagree. }
\end{array}
$$

o Neither agree nor disagree.

$$
\begin{aligned}
& \text { o Slightly o Strongly } \\
& \text { disagree. disagree. } \\
& \text { o Slightly o Strongly } \\
& \text { disagree. disagree. }
\end{aligned}
$$

o Neither agree nor disagree.
o Neither agree nor disagree.

o Strongly disagree. disagree.

o Neither agree nor disagree.

o Slightly

o Strongly disagree. disagree.

o Strongly agree. o Slightly agree.

o Neither agree

o Slightly

o Strongly nor disagree. disagree. disagree.

o Strongly agree. o Slightly agree.

Neither agree
nor disagree.

$\begin{array}{rr}\text { o Slightly } & \text { o Strongly } \\ \text { disagree. } & \text { disagree. }\end{array}$

o Strongly agree. o Slightly agree.

$\begin{array}{ccc}\begin{array}{c}\text { o Neither agree } \\ \text { nor disagree. }\end{array} & \begin{array}{c}\text { o Slightly } \\ \text { disagree. }\end{array} & \text { o Strongly } \\ \text { disagree. }\end{array}$

